\title{
ARQUITETURA EFÊMERA E INSURGÊNCIA URBANA. ESTRATÉGIAS DE APROPRIAÇÃO DO COMÉRCIO AMBULANTE NOS ESPAÇOS INTERSTICIAIS DO BRT TRANSOESTE, RIO DE JANEIRO
}

Ephemeral architecture and urban insurgency. Strategies for the appropriation of street trading in the interstitial spaces of the BRT TransOeste, Rio de Janeiro.

\section{Arquitetura efímera e insurgencia urbana.}

Estrategias de apropiación del comercio ambulante en los espacios intersticiales del BRT TransOeste,

Río de Janeiro.

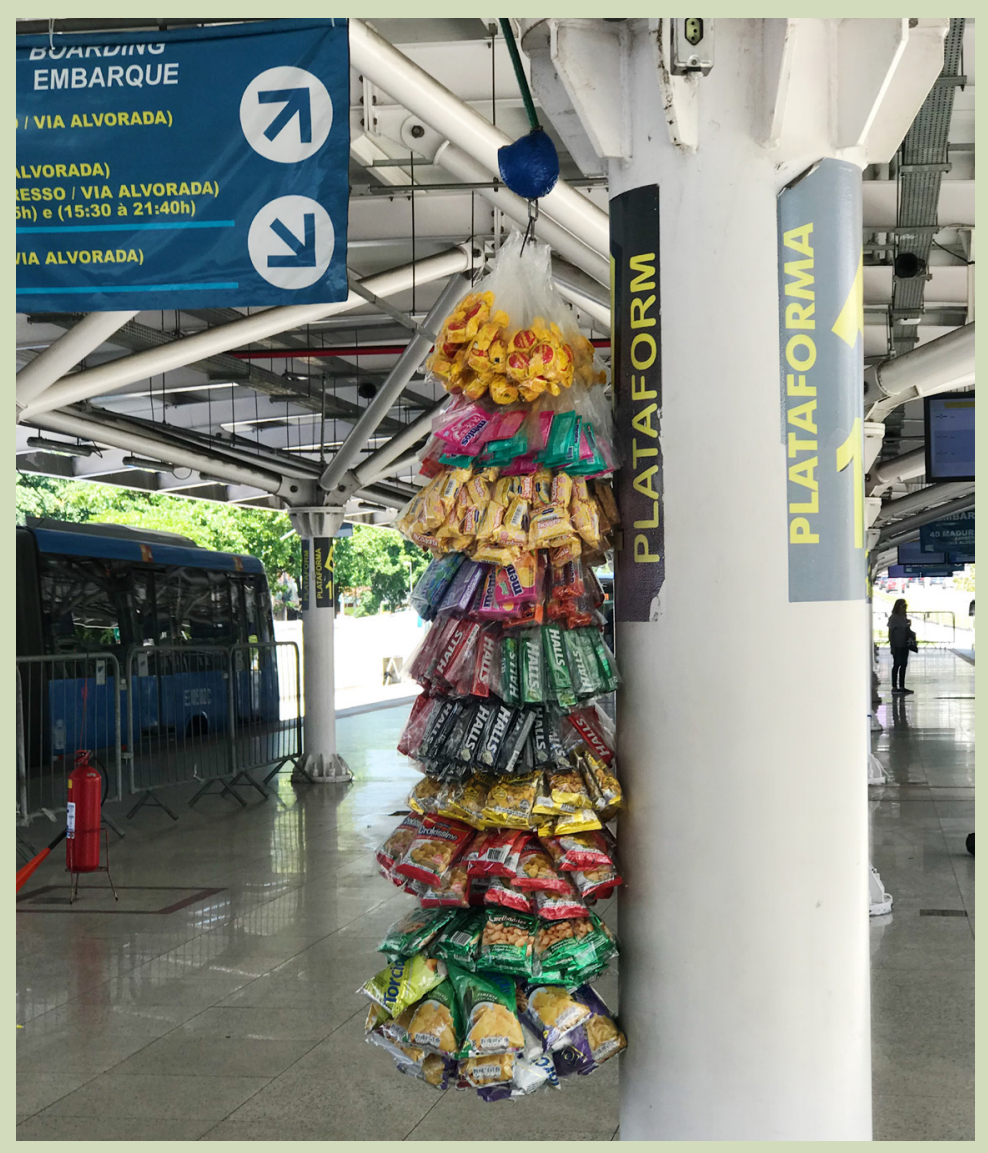

Fernando Espósito Galarce

Professor Assistente do Departamento de Arquitectura e Urbanismo, Professor pesquisador do Programa de Pós-Graduação em Arquitetura. Pontifícia Universidade Católica do Rio de Janeiro. Rio de Janeiro. Brasil.

fernando.esposito@puc-rio.br

https://orcid.org/0000-0001-9441-6012

\section{Amanda Senna Pettená}

Arquiteta. Bolsista de Iniciação Cientifica (Bolsa TEPP 2016-2018). Pontifícia Universidade Católica do Rio de Janeiro. Rio de Janeiro. Brasil.

amandasennap@gmail.com

https://orcid.org/0000-0002-0417-9920

Proyecto:

Bolsa de Produtividade em Pesquisa PUC-Rio e Bolsa Tutoria de Ensino e Pesquisa da PUC-Rio (Bolsa TEPP)

Gancho com produtos de comércio

ambulante pendurados em um dos pilares da estrutura da estação intermodal Jardim Oceânico do BRT Transoeste, Rio de Janeiro. Fuente: Fernando Espósito y Amanda Senna Pettená 


\section{RESUMO}

A cidade do Rio de Janeiro passou por importantes obras de reestruturação urbana ao longo da última década. Sua condição de cidade sede da Copa do Mundo de 2014 e das Olimpíadas de 2016 significou um importante processo transformador para grande parte da cidade. Nesse contexto, uma das intervenções infraestruturais mais importantes dentre as executadas foi a implementação do sistema de BRTs (Bus Rapid Transit). Na maioria das estações é possível perceber uma dinâmica informal de usos não programados e apropriações efêmeras por meio de objetos ou dispositivos de comércio informal que ocupam os "interstícios" deixados pelo sistema. Essa insurgência reivindica novas possibilidades de leitura dos espaços urbanos, uma vez que revelam suas potencialidades, oferecendo alternativas de serviços e produtos no contexto da mobilidade cotidiana. O conceito de intersticialidade é proposto em resposta à necessidade de caracterizar o "entre", as brechas no sistema de BRT, que na prática, possui limites difusos. O que enuncia essa dimensão intersticial são os habitantes e usuários dessas brechas, por meio da apropriação efêmera desta infraestrutura e seu entorno. Através do trabalho de campo, levantamento fotográfico, categorização das condutas observadas e dos suportes efêmeros detectados, complementados com uma discussão bibliográfica, este trabalho observa essas apropriações efêmeras nos espaços intersticiais principalmente da Estação Intermodal Jardim Oceânico do corredor TransOeste do sistema de BRT carioca. O trabalho conclui que o fenômeno da apropriação intersticial deve ser considerado como parte dos sistemas urbanos, pois, na cidade contemporânea, é essa efemeridade insurgente e informal a que muitas vezes responde às demandas e necessidades do nosso cotidiano.

Palavras chave: Espaços intersticiais, mobilidade urbana, análise urbana, arquitetura efêmera, apropriação.

\section{RESUMEN}

La ciudad de Río de Janeiro pasó por importantes obras de reestructuración urbana en la última década. Su condición de ciudad anfitriona de la Copa del Mundo 2014 y los Juegos Olímpicos 2016 significó un importante proceso de transformación de gran parte de la ciudad. En este contexto, una de las intervenciones de infraestructura más importantes fue la implementación del sistema de BRTs (Bus Rapid Transit). En la mayoría de las estaciones es posible percibir una dinámica informal de usos no programados y apropiaciones efímeras, a través de objetos o dispositivos de comercio informal que ocupan los "intersticios" que deja el sistema. Esta insurgencia reivindica nuevas posibilidades de interpretación de los espacios urbanos, una vez que revelan su potencial, ofreciendo alternativas de servicios y productos en un contexto de movilidad cotidiana. El concepto de intersticialidad se propone en respuesta a la necesidad de nombrar el "entre" o lagunas del sistema BRT, que en la práctica, posee límites difusos. Lo que visibiliza esta dimensión intersticial son los habitantes y usuarios de estos espacios "entre", a través de la apropiación efímera de la infraestructura de movilidad y sus alrededores. A través de trabajo de campo, levantamiento fotográfico, una categorización de las conductas observadas y de los soportes efímeros detectados, complementados con una discusión bibliográfica, este trabajo observa esas apropiaciones efímeras en los espacios intersticiales, principalmente de la Estación Intermodal Jardín Oceánico del corredor TransOeste del sistema de BRT carioca. El trabajo concluye que el fenómeno de la apropiación intersticial debe ser considerado como parte de los sistemas urbanos, pues, en la ciudad contemporánea, es esa efimeridad insurgente e informal la que muchas veces responde a las demandas y necesidades de nuestro cotidiano.

Palabras clave: Espacios intersticiales, movilidad urbana, análisis urbano, arquitectura efímera, apropiación.

\section{SUMMARY}

Rio de Janeiro has gone through major urban restructuration work over the last decade. Its status as host city of the 2014 World Cup and 2016 Olympic Games meant an important transformation process for most of the city. In this context, one of the most important infrastructural interventions made was the implementation of the BRTs (Bus Rapid Transit) system. In most stations, it is possible to perceive an informal dynamic of unscheduled uses and ephemeral appropriations, using objects or devices of informal commerce that occupy the "interstices" forgotten by the system. This insurgency reclaims new possibilities for interpreting urban spaces, once they reveal their potential, offering alternative products and services in the context of daily urban mobility. The concept of "interstitiality" is proposed in order to name the "in-between", or the gaps in the BRT system which, in practice, have diffuse limits. What sets out this interstitial dimension are those who inhabit and use the gaps, through ephemeral appropriation of the mobility infrastructure and its surroundings. This work, through fieldwork, photographic survey, a categorization of the observed behaviors and the ephemeral supports detected, complemented with a bibliographic discussion, observes those ephemeral appropriations in the interstitial spaces, mainly of the TransOeste Corridor Jardim Oceânico Intermodal Station of the BRT system of Rio de Janeiro. The work concludes that the phenomenon of interstitial appropriation must be considered as part of the urban systems, because, in the contemporary city, it is that insurgent and informal ephemerality that often responds to the demands and needs of our daily lives. 


\section{INTRODUÇÃO}

1 FIFA (Federação Internacional de Futebol). COI (Comité Olímpico Internacional).
Como muitas cidades, Rio de Janeiro também é uma sobreposição de intervenções infraestruturais que ao longo da sua história tentaram responder aos desafios urbanos por meio de diferentes projetos e recortes ideológicos. Os maiores impactos na cidade estão associados principalmente a projetos que têm como fim o transporte e a mobilidade. Operações de grande porte foram executadas para que objetos funcionais fossem implementados de modo a conectar lugares, fluxos e pessoas. Como exemplo, temos estações intermodais, terminais e viadutos que se entrelaçam e coordenam os deslocamentos na cidade.

A cidade do Rio de Janeiro ao longo da última década passou por grandes obras de reestruturação urbana. Sua configuração como cidade sede de megaeventos como os Jogos Pan-americanos de 2007, a Copa do Mundo de 2014 e as Olimpíadas de 2016, ativou um frenesi otimista e transformador em grande parte da cidade.

A organização de eventos como os mencionados responde a um planejamento estratégico, a partir do qual se projeta uma imagem positiva das cidades-sede no cenário internacional como ponto de atração de investimentos. Como pontuado por Raquel Rolnik (2015, p. 67), a estratégia de desenvolvimento econômico das cidades, que inclui a renovação da infraestrutura urbana e a abertura de novas frentes de expansão imobiliária relacionadas aos Jogos, é o enfoque hegemônico da realização dos megaeventos esportivos internacionais: é o chamado "legado urbano" do evento.

A retórica dos poderes públicos para justificar a organização de megaeventos e as transformações do espaço urbano que necessitam, baseia-se tradicionalmente nos benefícios em termos econômicos e de infraestruturas urbanas (Mendes; Legroux 20 I6, p. I5). No caso do Rio de Janeiro, a mobilidade urbana foi um tema que protagonizou a pauta das transformações.

De modo a cumprir exigências da FIFA e do COI1, órgãos organizadores da Copa 2014 das Olimpíadas 2016, respectivamente, equipamentos de mobilidade foram estruturados em conjunto com os estádios, arenas e pavilhões, empreendimentos comerciais e imobiliários. Passados os megaeventos, a dinâmica da cidade incorporou os novos empreendimentos e infraestruturas ao modus operandi cotidiano. Assim, infraestruturas de transporte mostraram-se superdimensionadas para a população que de fato os utiliza no dia-a-dia, como "elefantes brancos" que exigem custos altíssimos para manutenção, surgindo algumas incompatibilidades entre as estruturas viárias e o contexto urbano (Gonçalves, 20 I6). Além disso, existe uma discrepância entre a construção desses equipamentos e sua total integração posterior à vida econômica e urbana local (Whitaker, 2014, p. 12). Como colocado por Martin, existe um simbolismo associado a estas intervenções que "intoxica" a cidade. (Martin, 2018, p. 2l). 
Figura 1.

Mapa de localização

das linhas de BRT no

Rio de Janeiro.

Fonte: Autores
No caso do Rio de Janeiro, os projetos de transporte representaram mais da metade dos investimentos oficiais da Copa do Mundo como também das Olimpíadas, algo "nunca ocorrido na história da cidade e que levou os poderes públicos a falar de uma verdadeira revolução do transporte". (Mendes; Legroux, 2016, p. 16).

Como principais obras desses investimentos podem-se destacar a demolição da Via Elevada Perimetral entre 2013 e 2014, símbolo da reforma da cidade (parte do projeto do Porto Maravilha); a implementação do VLT (Veiculo Leve sobre Trilhos), inaugurado em 2016, conectando diferentes pontos do centro da cidade; a linha 4 do metrô, conectando a Zona Sul à Barra da Tijuca; a reforma dos trens suburbanos e a implementação de sistemas de teleféricos em algumas favelas.

Esta contextualização, embora geral, é importante para esta discussão, considerando que, em vários sentidos, os megaeventos respondem também a uma efemeridade por serem transitórios, temporários, atuando em diferentes escalas, porém, deixando marcas permanentes na estrutura e funcionamento da cidade.

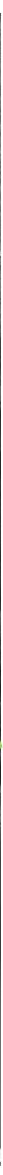


Nesse contexto, uma das intervenções infraestruturais de mobilidade mais importantes executadas nas últimas décadas na cidade do Rio de Janeiro e motivadas pelos megaeventos citados anteriormente, é o sistema de BRTs (Bus Rapid Transit).

BRT é um modal articulado que trafega em corredor exclusivo. No Rio de Janeiro atualmente estão em funcionamento três dos quatro corredores inicialmente propostos: TransOeste, TransCarioca e TransOlímpica [Figura I].

O TransOeste, o mais extenso de todos, é o primeiro corredor em operação da cidade, sendo inaugurado no dia 6 de junho de 2012, com o trajeto que liga a Barra da Tijuca ao bairro de Santa Cruz, na Zona Oeste. Apesar de ser uma linha que atravessa uma região de maior renda (Barra e Recreio), é utilizada basicamente pela população de menor renda dos bairros da Zona Oeste. $\bigcirc$ corredor TransCarioca, inaugurado em 2014, às vésperas da Copa do Mundo, liga o terminal Alvorada, na Barra da Tijuca, ao Aeroporto Internacional Tom Jobim, na Ilha do Governador, circulando ao longo de 39 quilômetros e 45 estações que interligam 27 bairros das zonas norte e oeste, fazendo integração com o trem da Supervia e Linha 2 do Metrô. A TransOlímpica, inaugurada em agosto de 2016, às vésperas dos Jogos Olímpicos, liga o Recreio a Deodoro, na zona norte, e conta com 18 estações e 3 terminais (Recreio, Centro Olímpico e Sulacap) em 26 quilômetros de pista exclusiva. $\bigcirc$ Transbrasil, quarto corredor proposto, ainda em obras, ligará Deodoro ao centro do Rio de Janeiro, completando assim o anel dos corredores de BRT com mais de $150 \mathrm{~km}$ de extensão.

BRT TransOeste é o que detêm o maior fluxo diário de passageiros (216 mil aproximadamente) ao longo de 60 quilômetros, 62 estações e 4 terminais (Alvorada, Santa Cruz, Campo Grande e Jardim Oceânico). Devido à grande aderência da população, a meta de 220.000 passageiros por dia é atingida principalmente pelo fato dos trajetos se classificarem como pendulares, ou seja, casa-trabalho. Está claramente destinado às classes de baixa renda das zonas de Santa Cruz e Campo Grande, que se deslocam economizando $40 \%$ do tempo que antes gastavam. Contudo, apesar de contemplar essa população, as infraestruturas viárias foram construídas justificando a completa remoção das comunidades Vila Harmonia, Restinga e Vila Recreio 2, deixando grande parte dos terrenos das ex-comunidades subutilizadas, revelando as contradições desse tipo de estratégia urbana.

Por outro lado, e como destacado por Lassance "a falta de articulação urbana de suas estações e vias segregadas atestam sua incapacidade de contribuir com a criação de espaços públicos significantes" (20। 8, p. 83). No nível da rua, ou seja, na escala do pedestre, são raros os casos em que a estação é implementada considerando espaços vitais de permanência, muito menos articulando conexões com a cidade. 
Reforçando esta questão, Manuel Herce afirma que essas intervenções pouco contribuíram em resolver os problemas urbanísticos dos lugares onde foram construídas, principalmente porque "foram concebidas pensando no seu objeto principal, o transporte, e não nos requerimentos dos lugares que atravessam, dos espaços urbanos construídos" (2017, p. 88).

Levando em consideração os grandes investimentos e o potencial das infraestruturas de mobilidade de agregarem valor ao solo, estamos falando de espaços altamente valorizados em termos de conectividade, porém pouco férteis para expressões da vida urbana. É nessa brecha socioespacial onde germina o efêmero.

A fagocitose dos usuários sobre o sistema de BRT fez com que o modelo estandardizado começasse a delinear um caráter hibrido entre o programado e não programado e insurgente, visibilizando uma série de apropriações efêmeras sobre as infraestruturas urbanas permanentes de mobilidade, por meio da aplicação de uma inteligência empírica que ocupou os interstícios ${ }^{2}$ deixados pelo sistema. Essa insurgência manifesta o desejo de transformação do espaço urbano, por meio do uso e ocupação do espaço público, reivindicando novas possibilidades de leitura dos espaços urbanos e proporcionando uma criação paralela e eficaz no território (Lima 2014).

A principal manifestação dessa insurgência sistêmica é a economia informal que surgiu ainda com pouco tempo de funcionamento do BRT.Vendedores ambulantes, utilizando diversas estratégias, suportes e dispositivos para implementar sua atividade comercial, se misturam e entrecruzam com os usuários do BRT que entram e saem das estações, o que se dá com maior intensidade nos terminais e estações intermodais do sistema. Os comerciantes ocupam tanto o espaço interno da estação como o público entre a estrutura e as vias do entorno. Nesse contexto, é o caráter efêmero das ações, sustentado numa efemeridade física e na existência de uma intersticialidade espacial, que possibilita o fenômeno da apropriação. 


\section{MÉTODO}

Este trabalho analisa o fenômeno de apropriação e efemeridade urbana nos interstícios do BRT, observados especificamente na estação Intermodal Jardim Oceânico da Barra da Tijuca, um dos principais bairros do Rio de Janeiro.

Metodologicamente, segundo Groat e Wang (2013 apud Kowaltowski, D. C. C. K., \& Neves, L. de O.,2016) as pesquisas operam a partir de diversas técnicas e estratégias, entre elas as de caráter interpretativo histórico; correlacionadas; relação entre variáveis; experimentação; medições técnicas; pesquisa-ação; simulações e modelos; argumentação lógica; estudos de caso; qualitativa e estudo de campo. Neste caso, estando esta pesquisa sustentada na observação in loco, são as três ultimas estratégias metodológicas as que caracterizam principalmente este trabalho: estudo de caso, estudo de campo e qualitativa.

Essas observações e experiências registradas em campo se complementam com uma base teórico-conceitual, apoiada em autores que discutem conceitos como apropriação e infraestrutura. Esta articulação metodológica permite avançar sobre a interpretação, categorização e sistematização da dimensão observada: os interstícios e suas formas de ocupação efêmera.

O conceito de intersticialidade é proposto em resposta à necessidade de denominar o "entre", as brechas do sistema BRT, cujos limites são difusos. $O$ que enuncia essa dimensão intersticial são os habitantes e usuários dessas brechas, um fenômeno socioespacial de apropriação efêmera na infraestrutura dos Terminais de BRT e seu entorno.

A observação em campo foi desenvolvida por meio de percursos e visitas programadas em dias e horários de pico de fluxo, em conjunto com o levantamento cartográfico e fotográfico. As informações levantadas foram categorizadas em duas dimensões: Suportes e ações efêmeras. Os primeiros correspondem a elementos e objetos físicos e arquitetônicos presentes no espaço e que são passíveis de apropriação e utilizados de forma efêmera. As segundas são as ações que operam sobre os suportes, caracterizando os espaços intersticiais. A sistematização do levantamento feito em campo busca, desta forma, categorizar e espacializar as condutas observadas e os suportes efêmeros em que estas se apoiam. $\mathrm{Na}$ Tabela I, que será apresentada mais adiante, é possível identificar essas relações. 


\section{DISCUSSÃO E RESULTADOS}

\section{Percorrendo os interstícios da Estação Intermodal Jardim Oceânico do BRT TransOeste.}

A estação Jardim Oceânico se encontra em uma extremidade do corredor BRT Transoeste, num contexto urbano socioeconômico totalmente diferente do Terminal Santa Cruz. Como já apontado, a maioria dos trajetos são pendulares e o público-alvo do sistema são as classes de renda mais baixa. Em termos simples, Santa Cruz é a origem do deslocamento (casa) e o Jardim Oceânico é o destino (trabalho). 0 terminal Jardim Oceânico é um terminal intermodal que conecta o BRT ao Metrô Linha 4 (trecho que conecta a Barra da Tijuca às Zonas Sul e Centro).

Situado na Av. Armando Lombardi, o Terminal foi construído entre as pistas de alta velocidade que ligam a Barra da Tijuca à Zona Sul da cidade. A área nobre onde foi implementado é caracterizada por um contexto socioeconômico de alto poder aquisitivo.

O terminal, pelo intenso fluxo que comporta e por ser estação final de diversas linhas dos corredores BRT, conta com uma grande área de plataforma de embarque (193m de extensão). Devido a sua localização no canteiro central entre pistas de alta velocidade, o acesso se dá pelo nível superior, por duas passarelas, uma de cada lado da Av. Armando Lombardi [Figura 2].

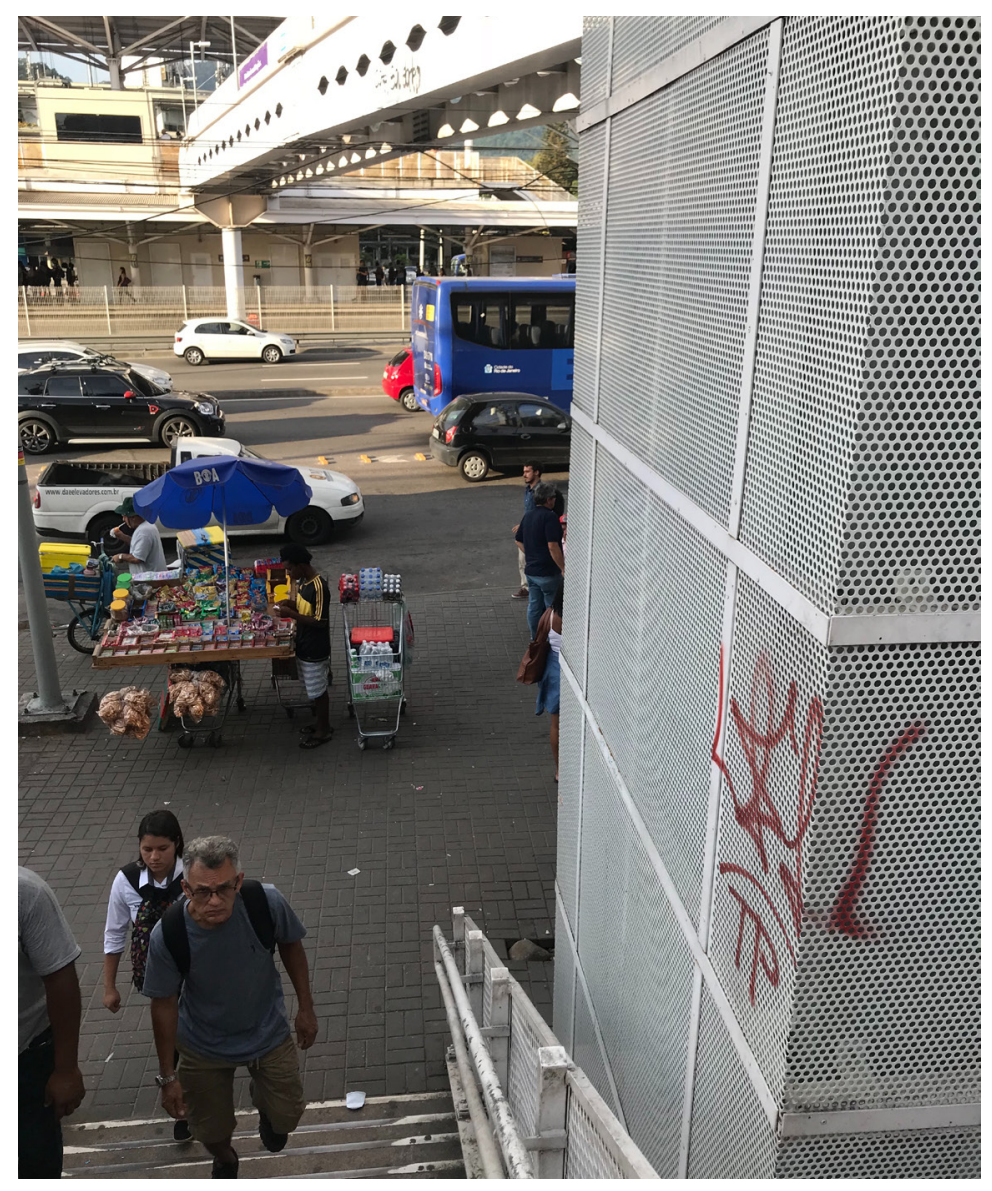

Figura 2.

Uma das passarelas

e sua relação com

a estação Jardim Oceânico (atrais). 0

fluxo de passageiros indo e vindo da estação se relaciona com o comércio ambulante localizado no espaço público. Fonte: Autores 
ARQUITECTURA EFÍMERA

Figura 4 e 5 Vista da passarela de acesso ao Terminal BRT Jardim Oceânico. O largo

onde a estrutura repousa é ocupado por vendedores ambulantes e carrocinhas que se localizam na projeção das sombras da torre do elevador, da passarela e das árvores. Fonte: Autores explica que existe uma rede de marcas de carrocinhas que distribui seus funcionários e mercadorias em todos os pontos de acesso ao BRT e Metrô. Ou seja, uma logística complexa de distribuição de produtos e administração de funcionários, com suas próprias normas de conduta destinada a aproveitar a brecha jurídica do sistema.

Do outro lado da avenida, a estrutura repousa sobre um pequeno largo onde há um ponto de ônibus gerando outra concentração de atividades. A estrutura também é utilizada como abrigo e sombreamento para vendedores ambulantes e pedestres que esperam os ônibus.

$\bigcirc$ ambulante Juliano de 34 anos revelou que ele trabalha com mais quatro parceiros, entre primos e irmãos, desde o início das atividades do Terminal, em agosto de 2016. Com a carrocinha de lanches se distribuem em todas os acessos do terminal além de dentro do Terminal de BRT com os ganchos (suporte das mercadorias). Se revezam para dormir no local e vigiar a mercadoria, que é armazenada sob a estrutura do terminal de ônibus na rua perpendicular à Av. Armando Lombardi. Das 6:00 às 22:00h eles mantêm a estrutura montada para dar cobertura a todos os horários de fluxo. Já que ocupam o interstício do Terminal há mais de dois anos, contaram já ter uma clientela fiel, a quem vendem fiado.
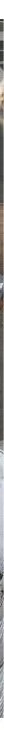




$\bigcirc$ acesso A do metrô (Saída Lagoa) também conta com usos não programados. Nesse caso, o contexto é uma praça projetada, que conta com bancos e vegetação. Ambulantes e comércios fixos, como a banca de jornal e um quiosque de pastel, dividem o espaço e estimulam a permanência dos transeuntes [Figura 6].

Dentro do Terminal do BRT o cenário é mais dinâmico, denso, com uma alta concentração de ambulantes. Com variados produtos, eles se conglomeram de modo a desviarem o intenso fluxo de passageiros. As condutas, mesmo com pouca oferta em termos de espaço, estabelecem novos usos e atividades para além do deslocamento. É claramente observada a capacidade de atribuir usabilidade à estrutura funcional. Dezenas de ganchos são pendurados nos tirantes de sustentação da cobertura. [Figura 7]. Grades, que servem para organizar as filas de embarque, são utilizadas como balcões de vendas. As paredes das construções de apoio e prisma de circulação vertical, dão suporte a esta apropriação efêmera por meio de diversos tipos de dispositivos [Figura 8]. 
ARQUITECTURA EFÍMERA
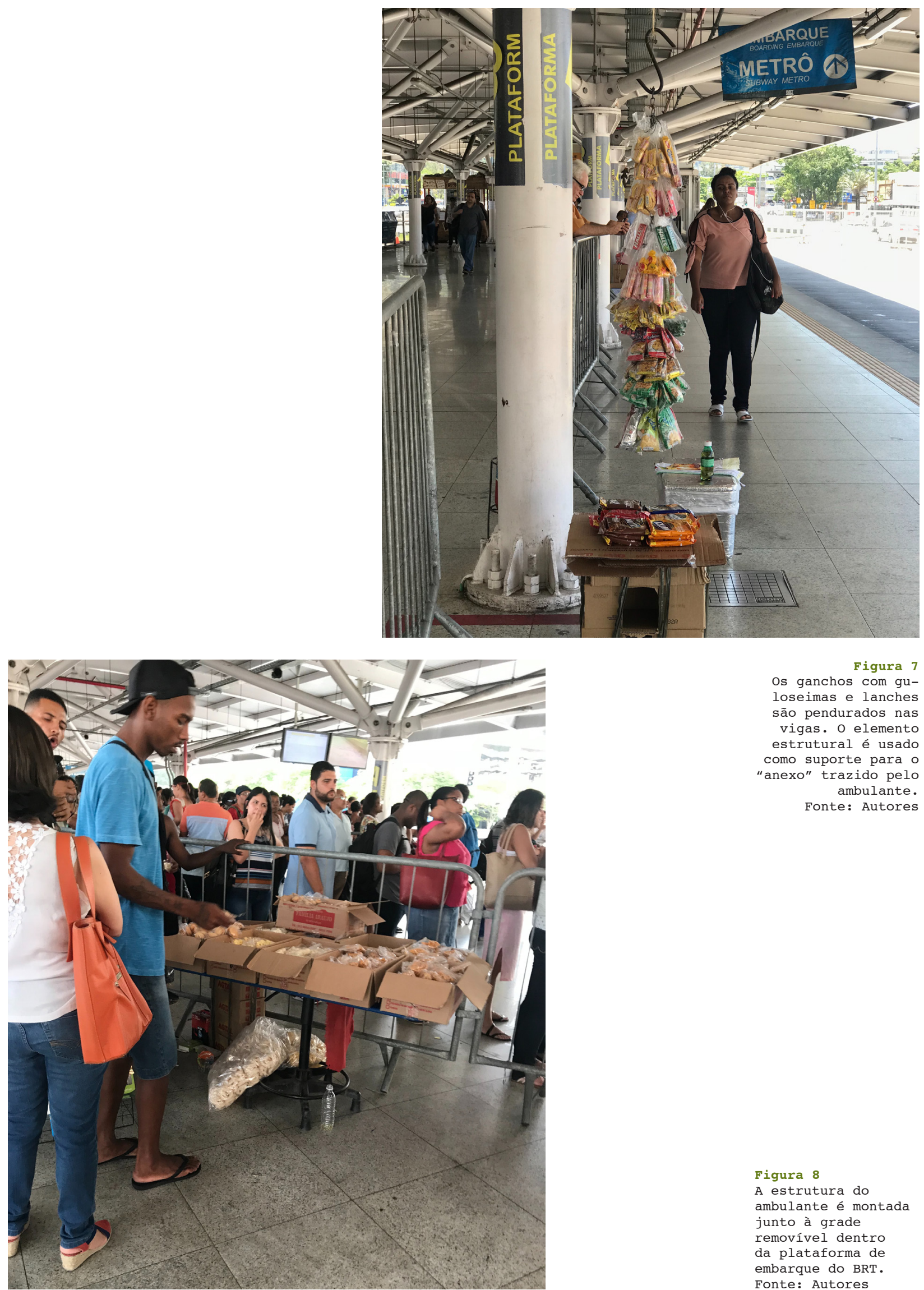

Figura 7

Os ganchos com guloseimas e lanches são pendurados nas vigas. O elemento estrutural é usado como suporte para o "anexo" trazido pelo ambulante. Fonte: Autores 


\begin{tabular}{|c|c|c|c|c|c|c|c|c|c|c|c|c|c|c|c|c|c|c|c|c|c|c|c|c|c|c|c|c|c|c|c|c|}
\hline & & \multicolumn{31}{|c|}{ AÇÕES EFÊMERAS } \\
\hline & & \multicolumn{5}{|c|}{ COMERCIALIZAR } & \multicolumn{5}{|c|}{ ARMAZENAR } & \multicolumn{5}{|c|}{ ESPERAR } & \multicolumn{5}{|c|}{ ESPERAR } & \multicolumn{5}{|c|}{ PICHAR } & \multicolumn{5}{|c|}{ APOIAR } & \\
\hline & & co & pu & pr & ef & $f_{x}$ & co & $\mathrm{pu}$ & pr & ef & $\mathrm{fx}$ & co & $\mathrm{pu}$ & pr & ef & $f x$ & co & pu & pr & ef & $\mathrm{fx}$ & co & pu & $\mathrm{pr}$ & ef & $f_{x}$ & co & $\mathrm{pu}$ & $\mathrm{pr}$ & ef & $f_{x}$ & co \\
\hline \multirow{16}{*}{ 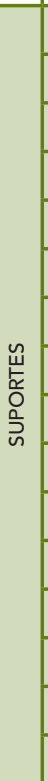 } & Largo & & $\mathrm{x}$ & & O & $x$ & & & & & & & $x$ & & $\mathrm{x}$ & & & $x$ & & 0 & & & $\mathrm{x}$ & & $x$ & & & & & & & \\
\hline & Árvore (sombra) & & $\mathrm{x}$ & & 0 & & & & & & & & $x$ & & $\mathrm{x}$ & & & $\mathrm{x}$ & & 0 & & & $x$ & & $x$ & & & & & & & \\
\hline & Escada & & & & & & $x$ & & & $\mathrm{x}$ & & & & & & & $\mathrm{x}$ & & & $\mathrm{x}$ & & $\mathrm{x}$ & $\mathrm{x}$ & & & $x$ & $\mathrm{x}$ & $x$ & & $x$ & & $x$ \\
\hline & Parede & & & & & & & & & & & & & & & & & & & & & $\mathrm{x}$ & $\mathrm{x}$ & & & $x$ & $x$ & $x$ & & $\mathrm{x}$ & & \\
\hline & Pilar & & & & & & & & & & & & & & & & & & & & & $x$ & $x$ & & & $x$ & $x$ & $x$ & & $x$ & & $x$ \\
\hline & Viga & & & & & & & & & & & & & & & & & & & & & $x$ & $\mathrm{x}$ & & & $x$ & & & & & & $x$ \\
\hline & Vão estrutural & & & & & & & & & & & & & & & & & & & & & & & & & & & & & & & \\
\hline & Reentrância & & $\mathrm{x}$ & & O & $x$ & $x$ & & & $x$ & & & & & & & & & & & & & & & & & & & & & & \\
\hline & Beiral (cobertura) & & & & & & & $x$ & & $x$ & & & $x$ & & $x$ & & & & & & & & & & & & & & & & & \\
\hline & Mureta & & & & & & & & & & & & $x$ & & $x$ & & & $x$ & & $x$ & & & & & & & & & & & & \\
\hline & Gradil & & & & & & & & & & & & & & & & & & & & & & & & & & $\mathrm{x}$ & $\mathrm{x}$ & & $\mathrm{x}$ & & $x$ \\
\hline & Mobiliário urbano & & $\mathrm{x}$ & & $x$ & & & & & & & & $x$ & & $x$ & & & $x$ & & $\mathrm{x}$ & & & $\mathrm{x}$ & & & $\mathrm{x}$ & & $x$ & & $\mathrm{x}$ & & \\
\hline & Desnivel & & & & & & & $x$ & & $x$ & & & & & & & & $x$ & & $x$ & & & & & & & & & & & & \\
\hline & Jardineira & & & & & & & $x$ & & $x$ & & & & & & & & $x$ & & $x$ & & & & & & & & $x$ & & $x$ & & \\
\hline & Beiral (laje) & & & & & & & & & & & $x$ & & & $x$ & & & & & & & & & & & & & & & & & \\
\hline & Rampa & & & & & & & & & & & $\mathrm{x}$ & & & $\mathrm{x}$ & & $\mathrm{x}$ & & & $\mathrm{x}$ & & $\mathrm{x}$ & $x$ & & & $x$ & & & & & & \\
\hline
\end{tabular}

Tabela 1

Sistematização das relações entre suporte e ações efêmeras.

Elaboração autores

A altura da viga, acessível ao braço do vendedor, permite que ele a utilize como apoio e monte um ponto de venda efêmero, físico e temporal. Abaixo do gancho há mais dois elementos: as caixas empilhadas e o isopor com bebidas. A sobreposição de caixas, com a lateral aberta e uma alça improvisada com fio de plástico, comprovam a engenhosidade para que todo o aparato seja facilmente desmontado e transportado quando o fluxo de passageiros diminuir na estação. A estrutura efêmera é montada junto ao limite da grade de modo que ambos os fluxos tenham acesso aos produtos: quem está na fila para entrar nos ônibus e quem está circulando pela periferia da plataforma.

$\bigcirc$ acesso $C$ ao metrô é o ponto de conexão entre o Terminal de BRT e a Linha 4. Já dentro da estação de metrô, devido às dimensões e aos mecanismos de controle institucionais mais rígidos (a brecha jurídica é mínima ou nula), não há a presença de ambulantes, apenas do comércio formal através de quiosques. Contudo, da mesma maneira que ocorre na plataforma do BRT, os módulos genéricos são implantados onde há interstícios, com suportes que adotam as características de algo efêmero, sem realmente ser, "estratégia que reproduz referentes de identidade na construção de cidadania e participação" (Herrera, Ledezma, 77, p. 20।4), ou seja, uma forma de mimetismo. 


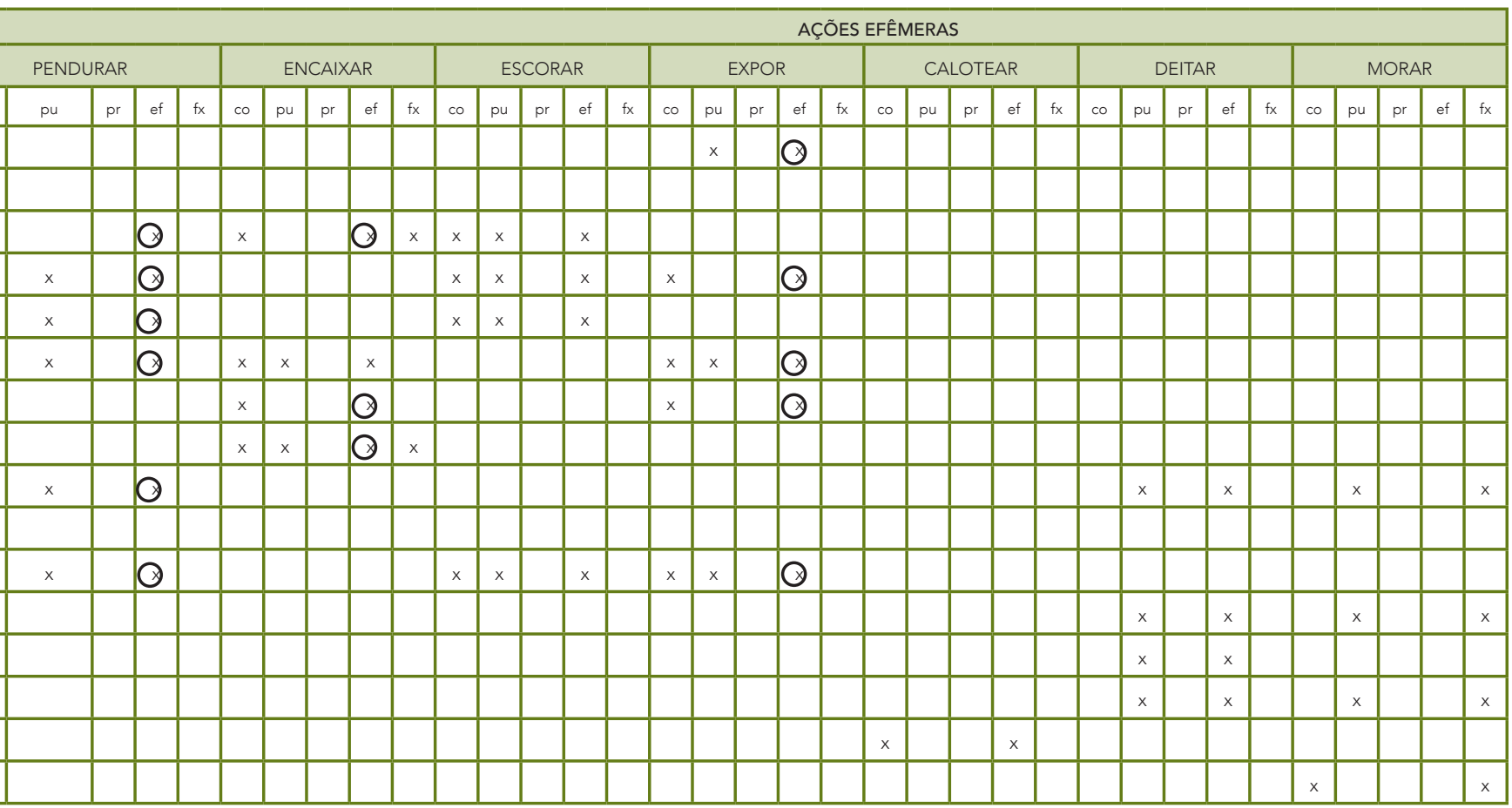

\begin{tabular}{|c|c|}
\hline \multicolumn{2}{|c|}{ LEGENDA } \\
\hline $\mathrm{co}$ & Concessionado \\
\hline $\mathrm{pu}$ & Público \\
\hline $\mathrm{pr}$ & Privado \\
\hline ef & Efêmero \\
\hline $\mathrm{fx}$ & Fixo \\
\hline $\mathrm{O}$ & Dispositivo intermediário \\
\hline
\end{tabular}

Estas ocupações e condutas se repetem em diferentes pontos da estação e, em geral, ao longo do sistema, especialmente em estações terminais e intermodais.

A partir do observado, foi possível enumerar as ações identificadas, bem como os suportes físicos nos quais se apoiam, estabelecendo uma relação entre apropriação e infraestrutura. Algumas dessas ações são empreendidas através de "dispositivos intermediários", ou seja, um elemento efêmero que viabiliza a apropriação temporária. É importante ressaltar que ações como "montar e desmontar" estão sempre associadas à presença desses dispositivos. Entre as ações e suportes físicos identificados são estabelecidas relações [Tabela I]. As categorias temporal e jurídica são sobrepostas a esse cruzamento, adicionando duas camadas que conferem complexidade à análise combinatória. Assim, é possível visualizar que a associação da ação com o suporte acontece em função do componente temporal (permanente ou efêmero) e jurídico (público, privado e concessionado) e que, em alguns casos, precisa de dispositivos intermediários como ganchos, caixas, mesas, carrinhos, entre outros, para efetivar a apropriação efêmera. 


\section{Espaços intersticiais como descompasso escalar entre infraestrutura e arquitetura}

Como observado no caso do BRT, a escala arquitetônica muitas das vezes fica relegada a um segundo plano, surgindo uma margem interescalar e interprogramática. Configura-se assim o espaço não programado, com fragmentos apropriáveis deixados à deriva. Dessa forma a possibilidade de se deparar com o indefinido e apropriar-se de um espaço resgata a autonomia cidadã respaldada na imprevisibilidade. No caso dos ambulantes observados na estação, suas condutas são capazes de configurar lugares, em uma certa residualidade espacial gerada pelo sistema, depreciada por ele mesmo, porém, valorizada pelos ambulantes. São, portanto, lugares nos que estes valores residuais podem prosperar, "apesar de sua completa desafeição da atividade da cidade, lugares estranhos que ficam fora das estruturas produtivas." (Solà-Morales, 20 I2, p. 4)

Por outro lado, se observarmos mais atentamente os espaços intersticiais apropriados do BRT e as dinâmicas socioespaciais que neles acontecem, "o que parece crucial é certa indefinição projetada no sistema, espaços deixados desocupados, espaços deixados livres para desenvolvimento imprevisto" (Allen S., 1999. Tradução Favero. 2017, p. 188). Esses espaços surgem como uma oportunidade para subverter dogmas funcionais. Gerar permanências em meio do fluxo caótico de um terminal ou estação, onde o objetivo comum é deslocar-se, revela a potência desses espaços. Demonstram que, apesar de improdutivo, impreciso e incerto, o espaço intersticial também é urbano.

A origem deste fenômeno é que existe um descompasso escalar entre o infraestrutural e o arquitetônico no contexto urbano que é o que define e origina o interstício. São espaços intermediários, entre fluxo e permanência, entre o projetado e o improvisado, em que a apropriação subjuga elementos funcionais do sistema ao status de suporte. É o que observamos no caso dos ganchos, caixas, isopores, entre outros dispositivos intermediários que, relacionados aos suportes como vigas, grades, tirantes, pilares, paredes, calçadas, corredores e passarelas, possibilitam ações e condutas que geram uma vitalidade ao lugar, tanto dentro da estação como no entorno, no espaço público. Desta forma o insurgente complementa o funcional, e a infraestrutura, interpretada a partir da arquitetura, tem o potencial de ser ponto de apoio da expressão apropriativa.

Uma intervenção da proporção do BRT e suas estações, em um contexto urbano de morfologia consolidada, é potencialmente capaz de estender seu espectro reestruturador não apenas ao limite espacial no qual está sendo implementado, mas também à interação das pessoas com o objeto e entre elas. Um novo contexto é gerado em torno de uma infraestrutura de mobilidade, uma tensão entre a constante condição de passagem e a permanência, o que promove novos usos e necessidades, além da mobilidade.

A articulação de novos usos deriva da aplicação de uma inteligência empírica aos componentes do artefato infraestrutural, respaldada na observação cotidiana e em demandas individuais ou de grupos, 


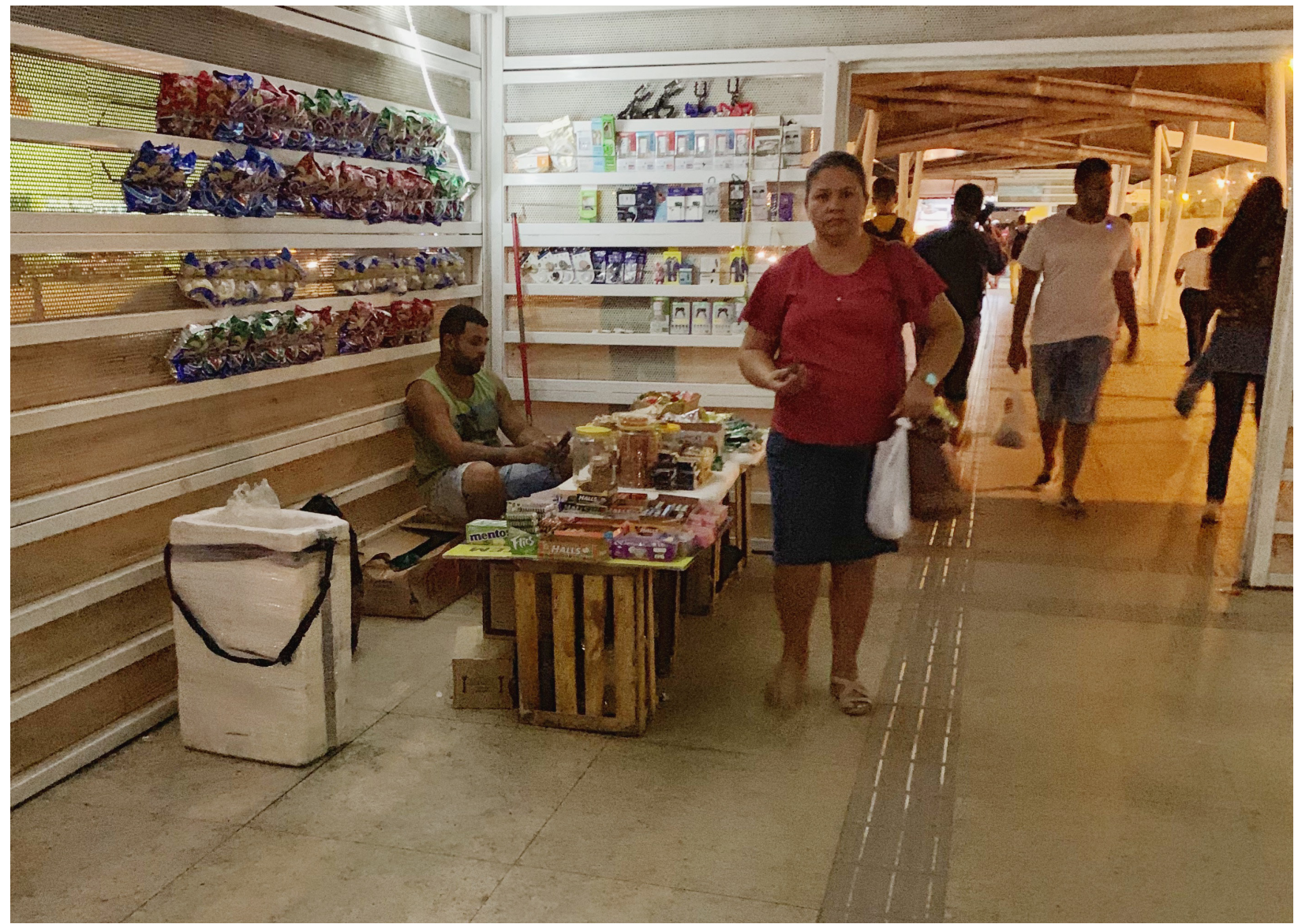

Figura 9

Estação Salvador

Allende. Apropriação

comercial ambulante

dentro da estação.

Fonte: Autores sendo possível perceber o caráter transformador e subversivo das atividades não programadas nas brechas apropriáveis do sistema. Assim, e por meio de uma arquitetura efêmera, é possível responder às problemáticas que muitas vezes o planejamento e a infraestrutura não respondem. Jaime Lerner (20I I, p. 3I) denomina esse tipo de ação de "acupuntura urbana". Pequenas ações que redefinem um contexto urbano da escala arquitetônica dentro de uma escala maior, atuando nas brechas esquecidas pelo sistema, "identificando o que falta, incorporando atividades e estimulando mais vida". Por exemplo, na estação Salvador Allende [Figura 9], um vendedor ambulante monta sua estrutura de trabalho utilizando o espaço entre fluxos. A pele metálica da plataforma de embarque é utilizada como suporte para a luz de led por ele instalada. $\bigcirc$ balcão de vendas é constituído por caixotes de feira alinhados. Uma nova função foi atribuída a um elemento compositivo da estrutura da estação. Os caixotes e o isopor se inserem como dispositivos intermediários que viabilizam a ocupação do espaço para o comércio. 


\section{O conceito de apropriação}

À luz das observações e experiências registradas no trabalho de campo se faz necessário refletir sobre o conceito de apropriação, para, como propósito geral, apontar possíveis desdobramentos a partir do caso estudado e, como propósito mais especifico, contribuir na compreensão do mesmo.

Para Enric Pol o processo de apropriação pode ser entendido a partir do que ele denomina "modelo dual", em que esse complexo fenômeno se decompõe em duas componentes: "Ação-transformação e identificação simbólica". (Pol, 2002, p. I24). Por um lado, "a componente ação-transformação é de base comportamental. Mediante a ação sobre o entorno a pessoa e a coletividade transformam o espaço, deixando sua impressão, e o incorporam em seus processos cognitivos e afetivos". (Pol, 2002, p. 124). Assim, de forma ativa, outorgam um significado social através da interação.

Por outro lado, "a componente identificação simbólica: Pela interação simbólica a pessoa e o grupo se reconhecem no entorno, e por processos de categorização do "eu" se auto atribuem qualidades como definidoras de sua própria identidade". Desta forma o espaço apropriado transforma-se em um fator de continuidade e estabilidade, gerando "apego" ao lugar. (Pol, 2002, p. 124).

Rita Velloso (2016) discorre sobre a apropriação segundo Lefebvre e Debord, concluindo que a experiência da apropriação é a compreensão do próprio indivíduo ou da coletividade, sendo essa a condição para a preservação, construção e reconstrução de sua práxis social. Apropriar-se então significa reconhecer a si mesmo no mundo, submetendo o espaço ao tempo vivido. $O$ uso, a interação entre $\mathrm{o}$ indivíduo e o espaço, ao final de um intervalo de tempo, determina a familiaridade deste com o lugar.

Dessa forma, o fenômeno da apropriação está apoiado na interação ativa do indivíduo ou grupo com o espaço e sua autoidentificação. As condutas humanas nos espaços intersticiais por parte dos usuários do sistema BRT TransOeste são, portanto, a submissão do espaço às necessidades identificadas, enquanto indivíduo ou enquanto grupo, de modo a desenvolver uma prática cotidiana e/ou impressão identitária.

Estas apropriações do efêmero por um lado podem ser interpretadas como subversões nos espaços do sistema de BRT, mas por outro, como expressões de conexão entre os diferentes níveis de habitabilidade dos espaços da mobilidade. Para Sennet (1997, p. 345) um dos grandes problemas é o espaço urbano ter se convertido em mero meio para fins de locomoção e transporte, deixando como consequência ruas e espaços públicos carentes de vida. Sennet também defende a ideia de que as experiências cotidianas, quando positivas, ajudam na recuperação de uma vida capaz de ser percebida com maior sensibilidade. Em uma cultura viva, o contato e a resistência urbana que implica o movimento 
são considerados uma experiência positiva. Nessas brechas de contato o efêmero oferece oportunidades, como visto no caso estudado.

Por outro lado, e como afirmado por Mello e Vogel (20 I5, p. 295), "o que não faz sentido não é passível de apropriação". Esse sentido de apropriação está associado a um espaço e tempo cotidiano e rotineiro dos usuários do BRT, tanto dos passageiros como daqueles que oferecem produtos e serviços, percebendo as demandas, oportunidades e ocupando as brechas intersticiais, algo que no bairro Jardim Oceânico da Barra da Tijuca, atravessado pela TransOeste, não era comum. Estas condutas enunciam o espaço ressignificado pelos usuários. Os elementos funcionais que compõem a infraestrutura são subjugados à condição de suporte, de modo a permitir que esse fenômeno se especialize, mesmo como subversão, pois, como afirmado por Agamben, na necessidade não existe lei a ser respeitada. Esta frase, segundo o autor, pode ser entendida em dois sentidos opostos. Por um lado, a necessidade não reconhece nenhuma lei, e por outra, a necessidade cria sua própria lei. (Agamben, 2004). Entre esses dois sentidos o efêmero gera lugar. 
Observar a relação entre infraestrutura e apropriação tem como objetivo tornar palpável a dimensão intersticial do espaço e a efemeridade do habitar. $\bigcirc$ efêmero surge como uma ação insurgente de apropriação, preenchendo espaços e respondendo às necessidades não previstas pelo sistema. No caso do BRT, é importante dar luz a este fenômeno, que deflagra uma dimensão desconsiderada no planejamento oficial pré-megaeventos e um poder público desatento às dinâmicas urbanas contemporâneas, com consequências graves na atualidade: um sistema de mobilidade pensado a partir de uma funcionalidade que opera com um imperativo de conectar pontos da cidade, porém, esquecendo as dinâmicas sócio espaciais próprias de um sistema de mobilidade como o BRT, que não só atravessa a cidade, mas também é absorvido pela mesma.

No caso da estação intermodal Jardim Oceânico, passageiros e comerciantes, tanto formais como informais, se misturam numa rede de acordos tácitos, confianças silenciosas, de ofertas e demandas cúmplices, muito além da formalidade sistêmica e funcional. Nesse contexto a arquitetura pode ampliar seu campo de ação como um ato de percorrer. Nos espaços de encontro e do caminhar a arquitetura pode reconhecer um meio no qual podem ser estimuladas novas modalidades de intervenção (Careri, 20।3, p. 33). No caso aqui apresentado, trata-se de uma concepção da cidade a partir de uma arquitetura efêmera e insurgente que responde ao não resolvido pela infraestrutura, mas sim à relação com a cidade e seus habitantes.

Compreender que a fagocitose do artefato é inerente à sua condição de infraestrutura, direciona o olhar para uma maneira de projetar que leve em consideração as apropriações efêmeras. Ao conferir usabilidade a elementos que são funcionais dentro do sistema de BRTs, percebemos o potencial de subversão e adaptação da inteligência empírica de seus habitantes, isto é, do valor do usuário no processo para que esses espaços genéricos e de apropriação efêmera sejam reconhecidos como parte dos sistemas urbanos. 


\section{REFERÊNCIAS BIBLIOGRÁFICAS}

AGAMBEN, G. (2004). Estado de exceção. Tradução: Iraci D. São Paulo: Boitempo.

ALLEN, S. (2017). Infraestructural Urbanism. Revista Prumo. Cidades Latino Americanas, v. 2 n. 3, 178-189. Recuperado de https://issuu.com/revistaprumo/ docs/prumo_3_vers_o_final__04_07_2017

CARERI, F. (2013). Walkscapes. O caminhar como prática estética. Barcelona: Editorial Gustavo Gili.

GONÇALVES, L. (2016). Mutações metropolitanas: estruturas viárias como lugar de apropriação, reinvenção e uso na cidade contemporânea. V!RUS, São Carlos, n. 13. Recuperado de <http://www.nomads.usp.br/virus/virus13/?se$\mathrm{c}=4$ \&item $=4$ \&lang $=\mathrm{pt}>$

HERCE, M. (2017). A ausência de projeto urbano nas obras de mobilidade no Rio de Janeiro. Revista Prumo. Cidades Latino Americanas, v. 2 n. 3, 86-92. Recuperado de https://issuu.com/revistaprumo/docs/prumo_3_vers_o_final_04_07_2017

JENNINGS, A. (2014). Brasil em jogo: o que fica da Copa e das Olimpíadas? 1 ed. - São Paulo: Boitempo: Carta Maior.

KOWALTOWSKI, D. C. C. K., \& NEVES, L. de O. (2016). A compreensão do projeto como tópico de pesquisa. PARC Pesquisa Em Arquitetura E Construção, 7(2), 58-60. Recuperado de https://doi.org/10.20396/parc.v7i2.864797

LASSANCE, G. (2017). Sobre a oportunidade de um legado olímpico para o Rio. Revista Prumo. Cidades Latino Americanas, v. 2, n. 3, 76-85. Recuperado de <http://periodicos.puc-rio.br/index.php/revistaprumo/article/view/328>

LERNER, J. (2011). Acupuntura urbana. Rio de janeiro: São Paulo: Record.

LIMA, C. H. (2014). A cidade insurgente: estratégias dos coletivos urbanos e vida pública. Arquitetura revista (UNISINOS), v. 10, n. 1, 31-36. Recuperado de http://revistas.unisinos.br/index.php/arquitetura/article/view/arq.2014.101.04

MARTIN, R. (2018). Sobre infraestructura. Entrevista (Pedro Correa, José Lemaître). Revista ARQ. Edit. ARQ. n. 99, 12-27.

MELLO, M.; VOGEL, A. (2015). Lições da rua: O que um racionalista pode aprender no Catumbi. En: Pensando no Rio, politicas publicas, conflitos urbanos, e modos de habitar. Niterói: Intertexto. p. 289-315.

MENDES, A.; LEGROUX, J. (2016). BRT Transoeste: conflitos urbanos e contradições espaciais na "cidade atrativa". Revista Direito e Práxis. Rio de Janeiro, Vol. 07, N. 4, 13-42.

POL, E. (2002). Em R. García-Mira, J.M. Sabucedo y J. Romay (Eds.) Psicología y medio ambiente. Aspectos psicosociales, educativos y metodológicos. A Coruña: Asociación Galega de Estudios e Investigacion Psicosocial-Publiedisa Pagin.

RIVERA, N., LEDEZMA, M. (2014). La ciudad como valor e identidade. En: Identidad y espacio público. Ampliando ambitos y prácticas (77-95). SÁNCHEZ, Diego, Domínguez, Luis Ángel (org). Edit. Gedisa S.A., Barcelona.

ROLNIK, R. (2014). Megaeventos: Direito à moradia em cidades à venda. En: Brasil em jogo. O que fica da copa e das olimpíadas? (65-70) Edi. Boitempo, São Paulo.

SENNET, R. (1997). Carne y piedra: El cuerpo y la ciudad en la civilización occidental. Madrid: Editorial Alianza.

SOLÀ-MORALES, I. (2012). Terrain vague. Arquitextos Vitruvius. Recuperado de http://www.archdaily.com.br/br/01-35561/terrain-vague-ignasi-de-sola-morales

VELLOSO, R. (2016). Apropriação, ou o urbano-experiência. Arquitextos Vitruvius. Recuperado de https://www.vitruvius.com.br/revistas/read/arquitextos/16.189/5949. 